\title{
The relationship between number, position in the fruit and genotype of tomato seeds ${ }^{1}$
}

\author{
N. Kedar ${ }^{2}$ and K. Verkerk \\ Department of Horticulture, Agricultural University, Wageningen, The Netherlands
}

Received 2 January, 1968

\section{Summary}

The fertilization of ovules in flowers of tomato cultivars with regular shaped, fewloculed fruits, was found to progress from the blossom half to the stem half of the ovary. In fruits with a total seed number of 10 or less almost all seeds developed in the blossom half of the fruits. The percentage of seeds developing in the blossom half gradually decreased with an increase in the number of seeds per fruit, reaching an average of $55.5 \%$ in fruits with more than 60 seeds.

After pollination with two genetically different types of pollen, the proportion of seeds carrying certain seedling markers was in many cases found to be statistically different in the two fruit halves. Pollen tubes first reaching the ovary, appeared to fertilize an unproportionally high number of ovules situated in the blossom half of the ovary.

$F_{1}$ seeds, resulting from pollination of Lycopersicum esculentum with mixtures of pollen from $L$. esculentum and $L$. hirsutum, could be differentiated according to seed size. Seeds resulting from fertilization with $L$. hirsutum were definitely smaller than other seeds.

Some implications of the findings are discussed.

\section{Introduction}

The genotype of tomato seeds in segregating populations is generally considered to be independent of the relative position of the seeds in the fruit. The extensive literature in the field of breeding, pollination and fertilization of tomatoes contains only a single work (Richardson and Currence, 1953) indicating that the above concept might not always be true.

In the tomato, differences have been found in the efficiency of microgametes of various genotypes (Bohn and Tucker, 1940; Kedar et al., 1967). For some crops it has been shown (Mangelsdorf and Jones, 1926; Emerson, 1934; Barnes and Cleveland, 1963) that the phenomenon might be caused by differences in pollen tube growth. This might result in genetical differences between seeds from different parts

1 This article will also be published as Publication 301, Laboratorium voor Tuinbouwplantenteelt, Landbouwhogeschool, Wageningen, The Netherlands.

2 Present address: Faculty of Agriculture, The Hebrew University, Rehovot, Israel. 
of the fruit if the fertilization of egg cells in the ovary does not occur at random and independent of the position of the ovules in the ovary.

The present work was initiated in order to investigate some of these questions. It is dealing, first, with the relationship between the number and the distribution of seeds in the tomato fruit. Second, possible effects of naturally occurring differences in speed of pollen tube growth were imitated by successive pollinations with pollen carrying different seedling markers. Finally, the relative speed of pollen germination and of pollen tube growth was studied in vitro in several tomato lines. The results were applied in the following experiment on the effect of pollination with mixtures of 'fast' and of 'slow' pollen.

\section{The relationship between seed number and seed position in the fruit}

Materials and methods. Pollen was collected from several tomato mutants and cultivars grown in the greenhouse. Part of the pollen was diluted with Lycopodium powder and mixtures containing approximately $0.1 \%, 1 \%, 10 \%$ and $100 \%$ of pollen were prepared. The cultivars serving as female parents were the globular fruited Moneymaker, Ailsa Craig and Rm 20-27, a line with oval shaped fruits. The locule number of the above lines varies between 2 and 3. Eighty-five flowers were emasculated 1-2 days before anthesis and pollinated with the various pollen mixtures. Thirty-six fruits, harvested after reaching the mature green stage of ripening, were cross-sectioned as uniformly as possible and the seeds were extracted by conventional methods. The number of normally developed seeds in each of the two fruit halves was then counted. From several of the fruits the pericarp walls were removed and the position of the seeds was observed directly. Some observations were also made with multilocular and irregularly shaped fruits of other cultivars.

Results. Pollination of tomato flowers with diluted pollen resulted in a number of fruits with reduced seed number (Table 1). Among the 36 fruits harvested were 23 with 10 seeds or less. In 22 of the fruits, seeds had developed only in the blossom half of the fruits, while in one fruit with 10 seeds 9 were situated in the blossom half. The results are illustrated in Figures 1 and 2. Figure 3 indicates, that with an increase in seed number, an increasing proportion of the seeds developed in the stem half. Thus, in 7 fruits of Moneymaker type resulting from pollinations with $100 \%$ pollen and with a seed number per fruit between 68 to 140 , approximately $55 \%$ of the seeds had developed in the blossom halves.

As the above, rather limited, material did not allow any final conclusions, the experiment was extended to include data from a total of 158 fruits of Moneymaker type collected at random in the greenhouse. Again, it was found (Table 2), that in fruits with a small number of seeds the proportion of seeds developing in the blossom half was relatively high, reaching about $83 \%$. With an increase in the average number of seeds per fruit this value gradually decreased, reaching a minimum of $55.5 \%$ in fruits with more than 60 seeds. The seed ratio (blossom half: stem half) of the four groups of fruits characterized by different total seed number was compared by means of the chi $^{2}$-test for independence. The chi $^{2}$ of comparisons between any two groups was found to be highly significant with $\mathrm{P}<0.005$. The results clearly indicated, that the proportion of seeds in the two fruit halves was dependent on the total number of seeds per fruit, the smaller the seed number the greater the propor- 
Fig. 1 Fruit of Moneymaker with one seed in each locule, after dissection of pericarp wall. The single seed is located in the blossom half of the fruit (Pollination with $10 \%$ pollen in Lycopodium powder).
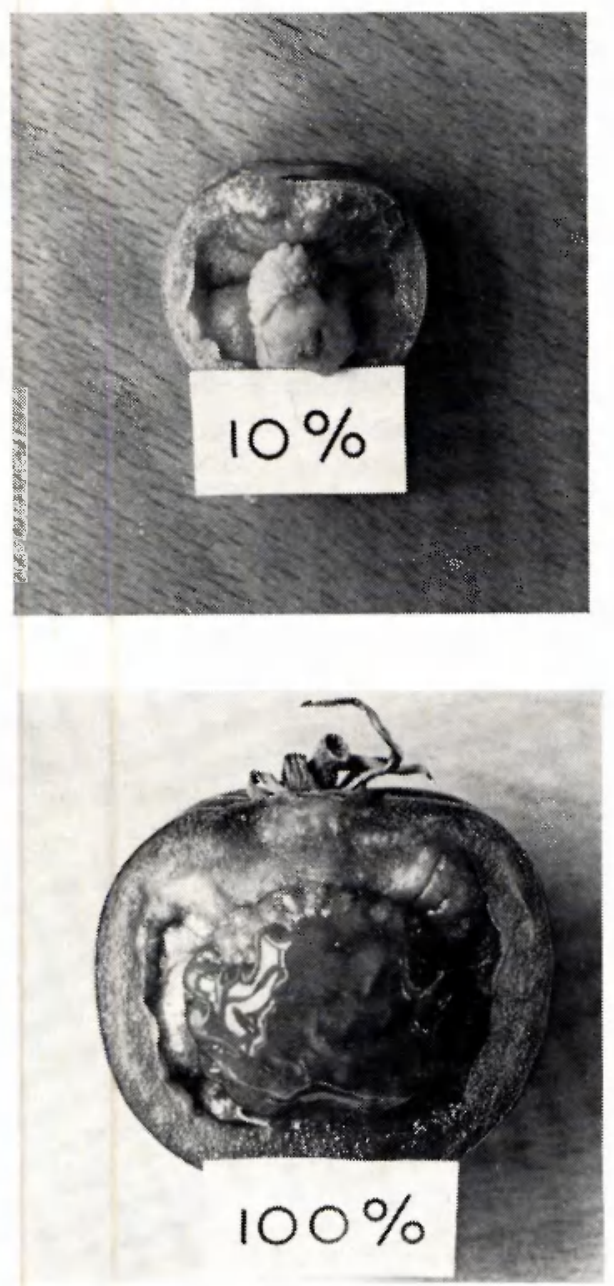

Fig. 2 Fruit of Moneymaker with 8 seeds in the two locules. All the seeds are located in the blossom half of the fruit $(10 \%$ pollen in Lycopodium powder).

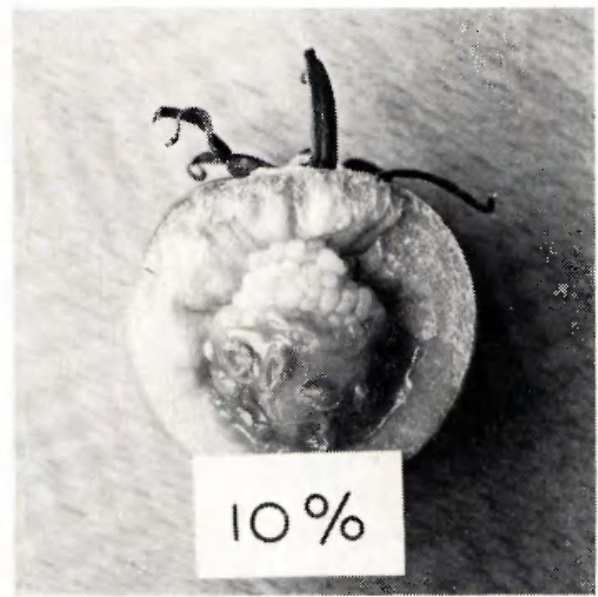

Fig. 3 Two loculed fruit of Moneymaker conraining 33 seeds, 27 of which were located in the blossom half (100\% pollen).

Table I Effect of pollen concentration on number of seeds per fruit

\begin{tabular}{lrrrr} 
& \multicolumn{4}{c}{$\begin{array}{c}\text { Percent of pollen in } \\
\text { Lycopodium powder }\end{array}$} \\
\cline { 2 - 5 } & $100 \%$ & $10 \%$ & $1 \%$ & $0.1 \%$ \\
Number flowers pollinated & 17 & 21 & 23 & 24 \\
Number fruits with seeds & 14 & 17 & 4 & 1 \\
Average number of seeds per fruit & 86.6 & 4.6 & 2.5 & 1.0 \\
\hline
\end{tabular}


Table 2 The relationship between number of seeds per fruit and the percentage of seeds developing in blossom halves of fruits of Ailsa Craig, Moneymaker and 6 Moneymaker mutants

\begin{tabular}{lrrrc} 
& \multicolumn{3}{c}{ Number of seeds per fruit } \\
& $1-20$ & $21-40$ & $41-60$ & $>60$ \\
& 52 & 32 & 25 & 49 \\
Number of fruits & 413 & 969 & 1248 & 5377 \\
Total number of seeds & 83.3 & 73.3 & 67.7 & 55.5
\end{tabular}

tion of seeds developing in the blossom halves of the fruits, and vice versa.

Several additional experiments which are not described here confirmed the above conclusions, as far as regularly shaped, 2-3 loculed, round or oval fruits are concerned. Contradictory results were obtained in some observations with multilocular, fasciated, irregularly shaped fruits, indicating possible effects of cultivar and fruit shape on the above relationship.

\section{Successive pollinations with genetically different types of pollen}

Materials and methods. The flowers were pollinated twice in order to test whether the pollen grains applied first would fertilize eggcells at random positions in the ovary. Eight tomato lines carrying the recessive alleles of certain seedling markers served as female parents. The flowers were emasculated before anthesis and were immediately pollinated with pollen from the cultivars Ailsa Craig and Moneymaker, both carrying the dominant alleles of respective seedling markers. In these pollinations the pollen was diluted to approximately $10 \%$ in Lycopodium powder. The second pollination was made $1 \frac{1 / 4}{4}$ to $171 / 2$ hours later with non-diluted pollen collected from the respective recessive mother lines. The fruits were harvested when ripe and the seeds from the two fruithalves were extracted separately. A maximum of 50 seeds of each fruit half was later seeded in boxes in the greenhouse and the number of seedlings with dominant seedling markers was counted.

Results. For few-loculed round fruited lines, the percentage of seeds carrying the dominant seedling marker was found (Table 3) to be on the average about 2.5 times greater in the blossom halves than in the stem halves of the fruits. Considering the total of the 6 mutant lines of common origin the ratio of 'dominant : recessive' in the two fruit halves was compared by the test for independence. The $\left[\mathrm{chi}^{2}\right]$ was 63.95 with $\mathbf{P}<0.005$.

The time interval between the first and the second pollination varied between $11 / 4$ and $171 / 2$ hours. The very limited material concerning this factor indicated, that a time interval of $1 \frac{1 / 4}{4}$ and $1 \frac{1}{2}$ was insufficient to cause observable differences between the two fruit halves in the percentage of 'dominant' seeds; an interval of 2 hours was sufficient, but still less effective than $7 \frac{1}{2}$ or $171 / 2$ hours.

Two lines with multilocular and more or less irregularly shaped fruits did not show significant differences between the two fruit halves. 
NUMBER OF SEEDS, POSITION IN TOMATO FRUIT AND SEED GENOTYPE

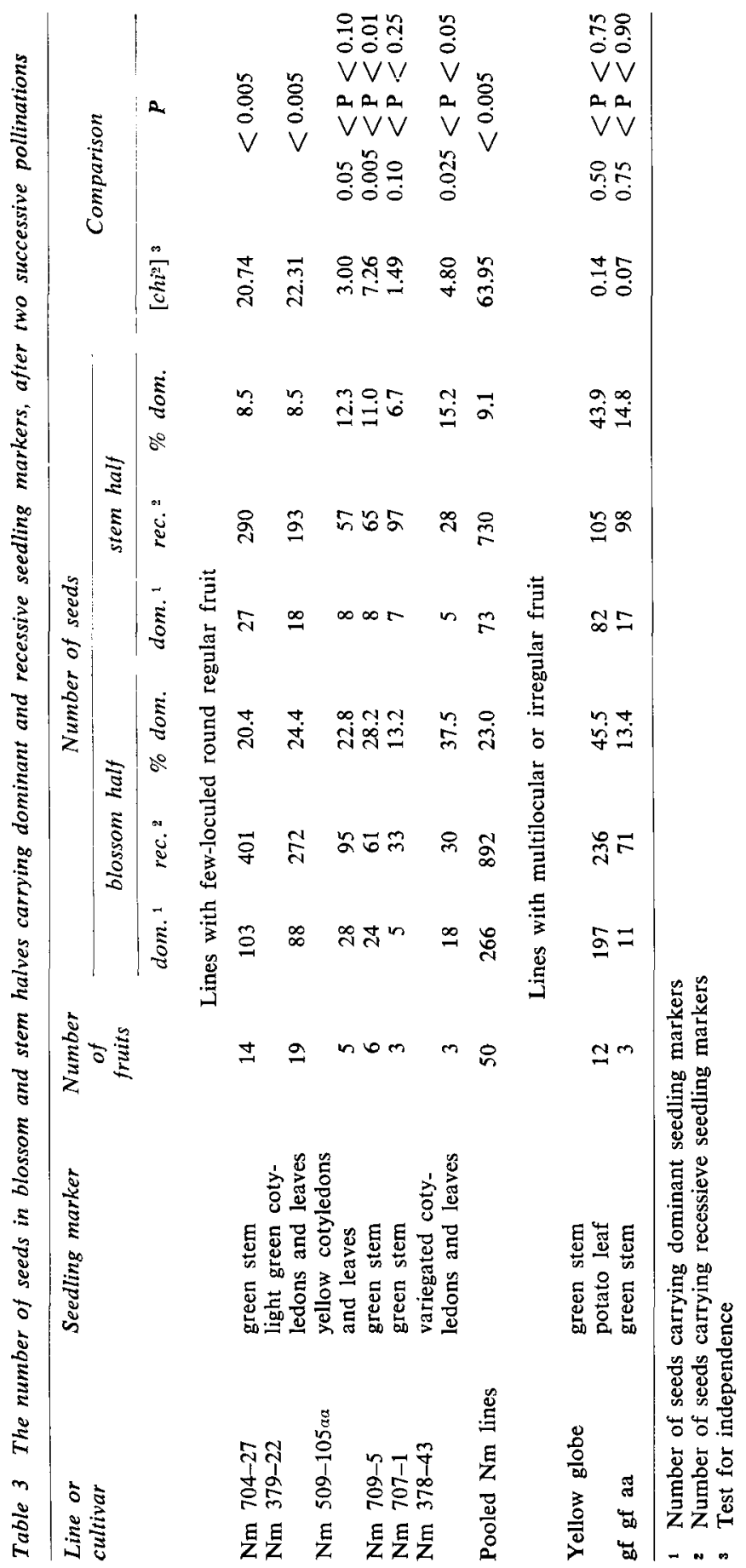




\section{Pollination with pollen mixtures}

Materials and methods. In a series of preliminary experiments pollen germination in vitro was investigated in 35 tomato lines and mutants. The pollen was germinated in hanging drops on the inside of petri dish covers. The medium for germination consisted of $7 \%$ saccharose and $60 \mathrm{ppm}$ boric acid in tap water. The petri dishes were kept at a temperature of $26^{\circ}-29^{\circ} \mathrm{C}$ and three drops of each sample were observed after 45,60 and 120 minutes. Based on repeated observations of pollen tube length at the above time intervals, the growth of the pollen tubes of different lines was found to range between very slow and fast. This characteristic was dependent on the rate of pollen germination and on the speed of pollen tube growth. Pollen characterized as 'fast' was diluted to $1 \%$ or to $10 \%$ in 'slow' pollen. After emasculation, flowers of mother plants were immediately pollinated by the above pollen mixtures. A total of 187 flowers was pollinated resulting in 93 fruits with seeds of two genetically different types. The seeds were extracted and planted as described in the previous experiment.

Results. In the earlier described experiment concerning two successive pollinations it was found, that diluted pollen applied first fertilized a relatively greater proportion of ovules in the blossom half of fruits than in the stem half. The question now arose, whether mixtures of 'fast' with 'slow' pollen would confirm these results. Table 4 mentions the material and Table 5 the results. Among the material were 55 fruits of Moneymaker, obtained after pollinations with a mixture of fast Money-

Table 4 Fruit and plant characteristics and pollen tube growth in vitro of tomato lines used in experiment with pollen mixtures of Table 5

\begin{tabular}{|c|c|c|c|}
\hline Line & Abbreviation & Relevant line characteristics & $\begin{array}{l}\text { Pollen tube } \\
\text { growth }\end{array}$ \\
\hline $\begin{array}{l}\text { Lycopersicum } \\
\text { hirsutum }\end{array}$ & hirs & $\begin{array}{l}\text { Very small fruits, anthocyanins in stem, } \\
\text { very small seeds }\end{array}$ & Very slow \\
\hline$a-\triangle$ & $a-\triangle$ & $\begin{array}{l}\text { Small fruits, anthocyanins in stem, narrow } \\
\text { leaves, short internodes, small seeds }\end{array}$ & Slow \\
\hline $\mathrm{Rm} 20-2 \alpha a$ & Rm 20-2 & $\begin{array}{l}\text { Rather small fruits; a yellow leaf mutant } \\
\text { of Moneymaker }\end{array}$ & $\begin{array}{l}\text { Slow to } \\
\text { medium }\end{array}$ \\
\hline $\mathrm{C}_{1}$ & $\mathbf{C}_{\mathbf{1}}$ & $\begin{array}{l}\text { Medium-sized fruits with } 3-6 \text { locules, green } \\
\text { stem, short internodes, potato leaf }\end{array}$ & Medium \\
\hline $\mathrm{C}_{2}$ & $\mathrm{C}_{2}$ & As $\mathrm{C}_{1}$ & Medium \\
\hline $\begin{array}{l}\text { Lycopersicum } \\
\text { pimpinellifolium }\end{array}$ & pimp & $\begin{array}{l}\text { Very small fruits, anthocyanins in stem, } \\
\text { small leaves }\end{array}$ & Fast \\
\hline Moneymaker & $\mathrm{Mm}$ & $\begin{array}{l}\text { Round fruits with 2-3 locules, anthocyanins } \\
\text { in stem }\end{array}$ & Fast \\
\hline Ailsa Craig & Ac & $\begin{array}{l}\text { Round fruits with } 2-3 \text { locules, anthocyanins } \\
\text { in stem }\end{array}$ & Fast \\
\hline
\end{tabular}


Table 5 Number of seedlings resulting from pollination by faster (+) or by slower (一) pollen in blossom and in stem halves of fruits, after application of pollen mixtures

\begin{tabular}{|c|c|c|c|c|c|c|c|c|c|}
\hline \multirow{2}{*}{$\begin{array}{l}\text { Mother } \\
\text { cultivar } \\
\text { or line }\end{array}$} & \multirow{2}{*}{$\begin{array}{c}\text { Father pollen mixture } 1 \\
\text { fast and slow }\end{array}$} & \multirow{2}{*}{$\begin{array}{c}\text { Number } \\
\text { of } \\
\text { fruits }\end{array}$} & \multicolumn{2}{|c|}{ Blossom } & half & \multicolumn{3}{|c|}{ Stem half } & \multirow[t]{2}{*}{ [chi?] } \\
\hline & & & + & - & $+\%$ & + & - & $+\%$ & \\
\hline $\mathrm{Mm}$ & $10 \% \mathrm{Mm}+90 \%$ hirs & 45 & 299 & 1719 & 15 & 93 & 1251 & 7 & 48.00 \\
\hline $\mathrm{Mm}$ & $1 \% \mathrm{Mm}+99 \%$ hirs & 10 & 30 & 627 & 5 & 11 & 530 & 2 & 5.83 \\
\hline $\operatorname{Rm} 20-2 \alpha \alpha$ & $10 \% \mathrm{AC}+90 \% \operatorname{Rm} 20-2 a \alpha$ & 6 & 26 & 88 & 23 & 20 & 78 & 20 & 0.19 \\
\hline $\operatorname{Rm} 20-2 a \alpha$ & $1 \% \mathrm{AC}+99 \% \operatorname{Rm} 20-2 a \alpha$ & 5 & 2 & 46 & 4 & 5 & 61 & 7 & - \\
\hline $\mathrm{Rm} 20-2 a \alpha$ & $10 \%$ pimp $+90 \% \operatorname{Rm} 20-2 \omega \alpha$ & 2 & 3 & 38 & 7 & 3 & 28 & 10 & - \\
\hline$a-\triangle$ & $10 \%$ pimp $+90 \% \alpha-\triangle$ & 6 & 19 & 83 & 19 & 10 & 57 & 15 & 0.39 \\
\hline $\mathrm{C}_{1}$ & $10 \%$ pimp $+90 \%\left(\mathrm{C}_{1}+\mathrm{C}_{2}\right)$ & 2 & 22 & 117 & 16 & 13 & 48 & 21 & 0.86 \\
\hline $\mathrm{C}_{1}$ & $10 \% \mathrm{AC}+90 \%\left(\mathrm{C}_{1}+\mathrm{C}_{2}\right)$ & 8 & 103 & 201 & 34 & 64 & 169 & 27 & 2.55 \\
\hline $\mathrm{C}_{2}$ & $10 \%$ pimp $+90 \%\left(\mathrm{C}_{1}+\mathrm{C}_{2}\right)$ & 5 & 23 & 113 & 17 & 13 & 78 & 14 & 0.31 \\
\hline $\mathrm{C}_{2}$ & $10 \% \mathrm{AC}+90 \%\left(\mathrm{C}_{1}+\mathrm{C}_{2}\right)$ & 4 & 114 & 134 & 46 & 66 & 93 & 42 & 0.85 \\
\hline
\end{tabular}

See Table 4

maker with very slow $L$. hirsutum pollen. Only this part of the material, consisting of 2-3-loculed round fruits, gave the expected results. The percentage of seeds resulting from fertilization by fast pollen was more than two times higher in the blossom half than in the stem half of the fruits.

Seeds resulting from Moneymaker pollen were relatively large, with an average 100 seed weight of $280 \mathrm{mg}$, while seeds derived from fertilization by $L$. hirsutum were definitely smaller, with an average 100 -seed weight of $118 \mathrm{mg}$. In a test sowing of large seeds, 63 out of 65 seedlings were of normal tomato type. In a similar test with small seeds, 272 out of 278 seedlings were of the $F_{1}$ type L. esculentum $\times$ L. hirsutum. Similar results have been reported by Lazarova (1961).

Table 6 The number of seeds per fruit and the distribution of seeds originating from fertilization by fast and by slow pollen, resulting in large and small seeds respectively, in blossom half and in stem half of the fruit

\begin{tabular}{|c|c|c|c|c|c|c|c|c|}
\hline \multirow{2}{*}{$\begin{array}{l}\text { Total } \\
\text { number } \\
\text { of seeds } \\
\text { per fruit }\end{array}$} & \multirow{2}{*}{$\begin{array}{c}\text { Number } \\
\text { of } \\
\text { fruits }\end{array}$} & \multicolumn{2}{|c|}{ Blossom } & half & \multicolumn{3}{|c|}{ Stem half } & \multirow{2}{*}{$\begin{array}{l}\text { Ratio \% large } \\
\text { blossom half: \% large } \\
\text { stem half }\end{array}$} \\
\hline & & large & small & $\%$ large & large & small & $\%$ large & \\
\hline$<50$ & 17 & 77 & 275 & 22 & 25 & 128 & 16 & 1.38 \\
\hline $51-100$ & 15 & 78 & 607 & 11 & 27 & 440 & 6 & 1.83 \\
\hline$>100$ & 13 & 144 & 837 & 15 & 45 & 675 & 6 & 2.50 \\
\hline
\end{tabular}

Whether or not the total number of seeds per fruit might have any effect on the distribution of seeds from fast and from slow pollen was tested for the 45 fruits of Moneymaker in top of Table 5. The results (Table 6) indicate, that with an increase in the total number of seeds per fruit relatively more ovules in the blossom half were pollinated by fast pollen than in the stem half. The $\left[\mathrm{chi}^{2}\right]$ for the distribution was 62.44 , indicating that this tendency was very strong. 


\section{Discussion and conclusions}

The present study indicates that the fertilization in the ovary of the tomato flower is not a process occurring entirely at random. In cases of relatively few pollen tubes reaching the ovary, ovules situated in the blossom half were fertilized almost exclusively. An increase in the number of pollen grains applied resulted in a greater number of seeds per fruit. This was accompanied by a gradual increase in the percentage of seeds developing in the stem half of the fruit, reaching a maximum of $44.5 \%$. Richardson and Currence (1953) found that $42 \%$ of the seeds were produced in the stem half of fruits. In their experiments, style removal 24 hours after pollination resulted in a decrease in the frequency of seeds produced in the stem halves from $42 \%$ to $33 \%$ and $36 \%$ in two cases. This difference was, however, considered too small to be conclusive.

The question was then investigated whether two successive pollinations with different types of pollen would give similar results. In lines with few-loculed round fruits, the kind of pollen applied first preferentially fertilized ovules in the blossom half of the flower. The ratio 'seeds produced by the earlier pollination: seeds produced by the later pollination' was on the average 2.5 times greater in the blossom half than in the stem half.

Our experiment was intended also to give some indication on the minimum time interval between two pollinations, sufficient to result in a non-random distribution of seeds of various genotypes in the two fruit halves. Because of the limited material, no final conclusions as to this question could be drawn. Some indications were obtained, however, that the minimum time interval between pollinations was approximately 2 hours under the conditions present. As could be expected, an interval of $71 / 2$ or $171 / 2$ hours was even more effective. These results can be understood considering that a period of 24 hours appears to be necessary for pollen germination and growth through the style (Judkins, 1939; Richardson and Currence, 1953). The time interval between pollination and fertilization of eggcells was found to be about 50 hours (Smith, 1935), but this interval certainly depends on experimental conditions. In the light of the previous experiments it could be expected, that striking differences between pollen of different genotypes in rate of germination and in speed of pollen tube growth would give clearly distinguishable results when two types of pollen were applied simultaneously. In our experiments with mixtures of pollen characterized in vitro as 'slow' and as 'fast' respectively, almost $60 \%$ of the fruits yielding seeds were of the cultivar Moneymaker. The seeds resulted from pollinations by a mixture of $1 \%$ or $10 \%$ 'fast' Moneymaker pollen with very slow germinating pollen of L. hirsutum. The results confirmed the earlier concept, that pollen tubes reaching the ovary first preferentially fertilized ovules situated in the blossom half of fruits. Yet, about $40 \%$ of the experimental material, divided between different combinations of mother plants and pollen mixtures, did not show significant differences between the fruit halves in the percentage of seeds carrying the dominant marker. Several factors might have been responsible for the above result. It might be, that only normal sized fruits of Moneymaker type show the expected distribution; there is, however, no reason to expect that the similarly shaped but smaller fruits of the Moneymaker mutant Rm 20-2 $\alpha \alpha$ should behave differently than Moneymaker. Another reason might be, that our classification of fast and slow pollen was based on in vitro observations and there is no proof that this classification holds true in vivo. Thirdly, the differences between lines in speed of pollen tube growth might have been too small to 
be effective. Significant results were obtained only after application of mixtures between fast pollen and the very slowly germinating hirsutum pollen.

An increase in the total number of seeds per fruit was found to be accompanied by a higher blossom half: stem half ratio of seeds derived from fast pollen. The reason for this statistically significant tendency might have been the increased competition between fast and slow pollen in flowers developing to fruits with high seed numbers. Richardson and Currence (1953) found some indication that in self-pollinated $F_{1}$ plants of a certain cross the seeds derived from stem halves gave plants genetically superior in early yield. Another treatment motivated by the assumption of genetical differences in speed of pollen tube growth was style removal 24 hours after pollination. According to the authors, this treatment probably caused the elimination of part of the pollen gametes carrying factors for flat fruit shape.

The work cited above as well as our present experiments indicated, that the process of fertilization in the tomato as well as in other plants, is not a random process as far as the choice of ovules in the ovary by male gametes is concerned (Barnes and Cleveland, 1963; Mangelsdorf and Jones, 1926). For Oenothera (Glenk, 1964) it has been concluded, that due to chemotropism, ovules at a certain optimal stage of development will be fertilized first. Accordingly, the sequence of fertilization is thought to depend on the stage of development of the ovary at the time of pollination. In our work, ovules appeared to be selected by pollen tubes according to their position in the ovary. This does not, however, exclude an explanation similar to that given for Oenothera.

The process of selective fertilization of ovules does in some cases lead to differences in the frequency of seeds of different genotypes in the blossom and in the stem half of fruits. In some cases this phenomenon might possibly be employed as an aid in breeding work. It might also be proof of value in selection and maintenance of pollen gametes advantageous under certain climatic conditions or in studies on the mechanism of non-random segregation in the tomato (Kedar et al., 1967).

\section{References}

Barnes, D. K, and Cleveland, R. W., 1963. Pol'en tube growth in diploid Alfalfa in vitro. Crop Sci. 3: 291-295.

Bohn, G. W. and Tucker, C. M., 1940. Studies on Fusarium wilt of the tomato. I. Immunity in Lycopersicon pimpinellifolium Mill. and its inheritance in hybrids. Mo. Agr. Expt. Sta. Res. Bul. 311: 1-82.

Emerson, R. A., 1934. Relation of the differential fertilization genes Gaga to certain other genes of the $S u-T n$ linkage group of maize. Genetics 19: 137-156.

Glenk, H. O., 1964. Untersuchungen über die sexuelle Affinität bei Oenotheren. In Pollen Physiology and Fertilization, Symposium, H. F. Linskens (Edit.), North-Holland Publ. Co. Amsterdam, p. $170-184$.

Judkins, W. P., 1939. Time involved in pollen tube extension through style and rate of fruit growth in tomato (Lycopersicum esculentum Mill.). Proc. Amer. Soc. Hort. Sci. 37 : 891-894.

Kedar, N., Retig, N. and Katan, J., 1967. Non random segregation of gene $I$ for Fusarium resistance in the tomato. Euphytica 16: 258-266.

Lazarova, R., 1961. Some pecularities in the hybridization of Lycopersicon esculentum and Lycopersicon hirsutum. Nauc. Tr. Viss. selskostop. Inst. G. Dimitrov, 9 : 221-230. (Bulgarian, from Hort. Abstr. 1962. V32(3) no. 5024).

Mangelsdorf, P. C. and Jones, D. F., 1926. The expression of mendelian factors in the gametophyte of maize. Genetics 11: 423-455.

Richardson, R. W. (Jr.) and Currence, T. M., 1953. Genetic effects of reduced fertilization in tomato flowers. Proc. Amer. Soc. Hort. Sci. $62: 449-458$.

Smith, Ora, 1935. Pollination and life-history studies of the tomato (Lycopersicon esculentum Mill.). Cornell Univ. Agr. Exp. Sta. Mem. 184: 3-16. 